\title{
Reconstruir as faces de Orestes
}

\section{Reconstructing Orestes: Three Faces of a Greek Character}

Jorge Deserto

Universidade do Porto, Porto / Portugal

Universidade de Coimbra, Coimbra / Portugal

jdeserto@gmail.com

Resumo: Orestes, o filho de Agamémnon, o assassino de sua mãe, Clitemnestra, tem, na literatura grega, várias faces, das quais três merecem, neste trabalho, tratamento especial: vingança, amizade, educação. Ele é o autor da mais terrível das vinganças, une-o a Pílades uma inquebrável amizade, constitui o modelo educativo que, no início da Odisseia, Atena propõe a Telémaco. E todas estas faces apresentam, de texto para texto, uma permanente mudança - o que torna Orestes uma personagem fugidia e difícil de definir, mesmo já na epopeia e no teatro gregos. Ao lermos algumas das reinvenções contemporâneas da figura de Orestes, interessa verificar de que modo nelas se assimila esse desenho prismático - aqui declinado num percurso breve por textos de Ruben A. (Um adeus aos deuses), Hélia Correia (O Rancor) e David Mourão Ferreira ( $O$ irmão).

Palavras-chave: Orestes; tragédia grega; recepção; Ruben A.; Hélia Correia; David Mourão Ferreira.

Abstract: Orestes, Agamemnon's son and the murderer of his mother, Clytemnestra, has in Greek literature several faces. Three of those faces will receive special treatment in this paper: revenge, friendship, and education. Orestes is the author of a most terrible revenge, he is united to Pylades by an unbreakable friendship, and he represents the educational 
paradeigma that Athena shows to Telemachus at the beginning of the Odyssey. All these faces are permanently changing from text to text and that makes of Orestes a character elusive and difficult to define, even if we are just talking about Greek epic and drama. When we read some of the contemporary rewritings of Orestes' myth, it is interesting to verify in what way they assimilate that prismatic drawing - here presented in a brief journey through the work of three Portuguese authors: Ruben A., Hélia Correia, and David Mourão Ferreira.

Keywords: Orestes; greek tragedy; reception; Ruben A.; Hélia Correia; David Mourão Ferreira.

Recebido em: 20 de março de 2017.

Aprovado em: 30 de junho de 2017.

Teria sido monótona a história da cultura se acaso Clitemnestra tivesse sido uma mulher séria.

(RUBEN A, Um adeus aos deuses, p. 89).

Seguir o caminho de uma figura do mito grego não é coisa que se faça sem fôlego. Seria fácil seguir-lhe o caminho se houvesse apenas um caminho a seguir. Mas as estradas multiplicam-se, cruzamse e entrecruzam-se, propõem vias paralelas, refazem passos já dados, desfazem esses passos e viajam em sentido inverso. O movimento é constante. As figuras do mito grego são quase impossíveis de retratar: o retrato fica sempre tremido, nunca ficam quietas tempo suficiente.

Uma forma singela, mas certamente eficaz, de caracterizar aquilo a que chamamos mitos gregos é afirmar que são narrativas em permanente reconstrução. Cada nova versão junta-se às anteriores, dialoga com elas, propõe e suscita efeitos de reconfiguração ou de releitura. De cada vez que um enredo é recontado, não deixamos de o poder ler na sua específica individualidade, na sua singularidade de intriga que se 
ergue independente de qualquer outra. Mas, ao mesmo tempo, porque ler um texto é sempre um exercício de memória, é impossível deixar de lado os outros momentos em que já nos confrontámos com variações daquele enredo ou com a presença daquelas personagens. Há nisso uma dificuldade - as diferentes versões nem sempre convivem de modo pacífico e isento de tensões -, mas há, acima de tudo, um potencial de enriquecimento que em muito ultrapassa o lado menos fácil.

Torna-se evidente e não necessita de particular demonstração que um dos exemplos que podem sustentar esta noção, a de que os enredos da mitologia permanentemente se renovam, é o caso de Orestes, enquanto figura central de várias e relevantes intrigas ao longo da literatura grega. O meu propósito final - e aí nos conduzirá a progressão do presente texto - é o de comentar, de forma breve, algumas releituras contemporâneas da figura do filho de Agamémnon, sempre em comparação com a fonte grega. Mas esse desiderato rapidamente se perderia, se fosse esquecido que, já no contexto grego, a narrativa de Orestes depressa se torna releitura - e releitura muitas vezes belicosa, pelo modo empenhado como, em alguns casos, se envolve em disputa com as versões anteriores. $\mathrm{O}$ fenómeno seria frequente e certamente se estenderia a outros núcleos de intrigas míticas, mas, neste caso particular, a fortuna de uma transmissão sempre cheia de imponderáveis legou-nos um amplo número de enredos nos quais Orestes tem importante papel: antes de mais, e com relevante dimensão, em Homero; depois em nomes como Estesícoro ou Píndaro; por fim, a presença simultânea nos três trágicos, fundadora em Ésquilo, interpelante em Sófocles, abrindo-se em amplo leque em Eurípides, autor que nos devolve vários Orestes, nem sempre capazes de se acolherem pacificamente à sombra da tradição que os antecedeu. Esta multiplicidade de intrigas recomenda-nos, desde logo, alguma cautela: reler Orestes, nos dias de hoje, é ter a noção de lidar com uma figura que constantemente nos foge e nos ilude o olhar. Mais ainda, reler Orestes, hoje em dia, é tomar como referência uma tradição na qual não é seguro que encontremos uma imagem consolidada. Fica, desde já, a questão, a que teremos de voltar: quando, nestes tempos contemporâneos, reencontramos Orestes, quando o tornamos, uma vez mais, agente e personagem, a que Orestes voltamos afinal? Eis uma questão que exige alguma demora. 
Avulta, em primeiro lugar, a trama mitológica, intensa, poderosíssima, na qual Orestes se inscreve. Toda a intriga em volta da casa dos Atridas se ergue a partir de uma infindável matéria, narrativa e dramática, recheada de figuras determinantes e inesquecíveis (sem ir mais longe, Atreu e Tiestes, Agamémnon, Clitemnestra e Egisto, Menelau e Helena, Ifigénia, Electra e Orestes...). Há nela raptos e guerras, traições e vingança - e sangue, muito sangue. Estes desgraçados descendentes de Tântalo e de Pélops parecem condensar em si, com insano fulgor, todo o vigor dos mitos gregos. Não será de admirar, por isso, que o escritor português Ruben A., a cuja obra regressaremos mais adiante, se sinta impressionado ao pisar, durante a sua viagem à Grécia, o solo da Argólida:

A Argólida é a região trágica do mundo - foi a origem de tudo quanto de máximo em motivo o génio humano conseguiu expressar. Sem a história da família dos Atridas, Homero seria um superhomem de fraca razão para falar aos deuses; Sófocles, Ésquilo, Eurípides, uns seres cheios de fome para procurarem outros reinos onde a tragédia remotamente manifestasse a força coordenada, emotiva, do carácter universal da imaginação criadora. (RUBEN A., 2010, p. 82).

Sem as histórias da casa de Atreu seríamos outros, como seriam outros, eventualmente, os caminhos de muita da literatura ocidental ao longo dos séculos. Certamente que alguns não deixariam de fazer, aqui, um ponto de ordem, para lembrar a extrema importância das intrigas em volta dos Labdácidas, para sublinhar o que devemos a toda uma linha narrativa construída em volta da casa real de Tebas. Rigorosamente verdade. Mas, sejamos claros, não se trata aqui de uma competição e convém que não nos afastemos do que é verdadeiramente importante.

De entre a profundidade e a força das intrigas em volta da família dos Atridas, Orestes, o filho de Agamémnon e Clitemnestra, assume, por assim dizer, um lugar culminante. É com ele que um ciclo incessante de vinganças chega ao fim, numa resolução que nem sempre assume a forma apaziguadora que eventualmente poderíamos esperar. Há várias 
perspectivas a partir das quais se poderia olhar para esta figura, todas elas potencialmente frutíferas. Escolhi decliná-la em três faces, todas elas distintas, mas que nos dão, depois de percorridas em conjunto, uma excelente imagem do irmão de Electra e do modo como, ao longo da literatura grega, ele já se apresenta como uma personagem em constante devir. São as seguintes, as três faces: vingança, amizade, educação.

Comecemos, naturalmente, pela vingança. Se há elemento que define esta personagem, é certamente este: o jovem que, vindo do exílio, regressa à terra pátria para vingar a morte do pai. Que essa vingança atinja Egisto, o usurpador do trono de Argos, eis algo que não levanta problemas e que apenas abona a favor da coragem do jovem filho de Agamémnon. O que torna singularmente perturbadora a vingança de Orestes é que ela toma por objecto, igualmente, a própria mãe. A punição de Clitemnestra será merecida - mas às mãos do filho? São as várias declinações deste insolúvel dilema - como vingar um pai ultrajado se isso significa tirar a vida à própria mãe? - que alimentam, em graus distintos, muitas das versões dramáticas deste enredo.

Convém notar, no entanto, que, antes disso, já nos havia sido proposto um outro caminho, mais simples, menos perturbador. $\mathrm{Na}$ Odisseia, a vingança de Orestes dirige-se apenas contra Egisto, e a morte de Clitemnestra é recoberta por um conveniente e adequado nevoeiro. Homero faz uma complexa gestão de silêncios e meias palavras - e de tal modo o faz que Orestes se torna digno de ser apresentado como exemplo, como veremos adiante. Isto não significa que Clitemnestra não tenha a sua dose de culpa, que o seu comportamento não sirva como forte contraste com a fidelidade e dedicação de Penélope. Mas a sua participação do crime chega-nos pela voz de Agamémnon (cf. XI, 405434) e é cuidadosamente elidida, antes, quando Telémaco ouve contar a história do regresso funesto do pai de Orestes (cf. III, 254-312; IV, 512537). Em suma, em Homero, na Odisseia, a morte de Agamémnon é a de um herói traído, a vingança de Orestes é um acto de bravura e arete, longe de qualquer dilema moral. Voltarei a este último ponto.

No teatro, tudo se torna mais denso. Se é certo que não deixa de haver mais do que um caminho, convém sublinhar que a leitura de Ésquilo, na Oresteia, assume o papel de versão fundadora e matriz. 
Em As Coéforas, a vingança de Orestes é um longo processo, no qual dramaticamente se conjugam, num crescendo meticulosamente desenhado, a vontade de um deus e a vontade de um homem. O problema não é, obviamente, Egisto, mas a necessidade de estender o acto de vingança a Clitemnestra. A ordem de Apolo, cuja credibilidade nunca é posta em causa, poderia ser já motivo suficiente para justificar o matricídio - mas Ésquilo, ao longo de um poderoso kommos, laboriosamente constrói a vontade daquele jovem, até que ele assuma como seu aquele acto terrível. Isso não o impede de, no momento decisivo, ser tomado por uma natural indecisão, que apenas revela e confirma a sua humanidade. Depois de consumada a vingança, protegido por Apolo e perseguido pelas terríveis Erínias, é ainda num momento de conciliação entre deuses e homens, sob o tecto acolhedor de Atenas (e da sua deusa tutelar), que Orestes se vê absolvido, num perdão que the devolve a dignidade, sem deixar de sublinhar até que ponto é iníquo o crime cometido. Num movimento inteligente, Ésquilo, em Euménides, desvia a nossa atenção de Orestes (ao qual não faz sentido, dadas as circunstâncias, outorgar uma absolvição triunfal) e desloca-a para a criação dessa nova ordem moral e cívica, na qual as divindades perseguidoras e sedentas de sangue, as Erínias, se transformam em entidades protectoras, sob o nome acolhedor de Euménides. A vingança de Orestes torna-se, afinal, um pretexto para mudar a ordem do mundo, para redefinir o relacionamento entre mortais e divindade, para enraizar um comportamento cívico no qual a polis ganha dimensão central. Este propósito maior enobrece e dignifica uma intriga até aí afogada em sangue e sofrimento.

O edifício construído por Ésquilo é tão perfeito que tudo o que vem a seguir se arrisca a ser lido como sucedâneo menor. E, ao mesmo tempo, temos a sensação de que o que vem a seguir se alimenta da estrada aberta pelo dramaturgo mais velho. Mesmo quando, como acontece com a Electra de Sófocles, o enredo parece tratar o matricídio como um não problema e resolvê-lo com a frieza de um acto mecânico. No entanto, este Orestes, a quem esta face da vingança parece não atormentar, é sensível ao sofrimento de Electra, a quem um relato fictício da morte do irmão havia conduzido ao mais completo desespero. $\mathrm{O}$ plano que dolosamente 
há-de atingir Clitemnestra tem perniciosos efeitos colaterais; o recipiente que, em Coéforas, transportava as libações através das quais as vontades dos dois irmãos se iriam unir à da divindade, evocada junto do túmulo do pai, transforma-se, em Sófocles, na urna que transporta, falsamente, as cinzas de Orestes, num jogo onde deixam de ser claras as linhas que separam verdade e mentira - desenhando Orestes com uma frieza que apenas o extremo sofrimento da irmã amacia.

Em Eurípides, é mais intensa a reversão, como é mais intensa também a presença tutelar de Ésquilo. Na Electra, o jovem príncipe carrega a vingança como um fardo, pressionado por um deus no qual não acredita, forçado por uma irmã (ela sim alimentada pelo fogo da vingança) que demora a reconhecer como sua. Essa relutância em assumir a sua identidade, esse retardar do reconhecimento são sinais de uma indecisão que se vai manter até ao fim, com Orestes, este Orestes, a sentir-se obrigado a vestir um fato que claramente não lhe serve no corpo. Quando a vingança se consuma, assistimos, num poderoso lamento final, ao horror de dois irmãos, cobertos pelo sangue da mãe, manchados pela ignomínia do crime que haviam acabado de cometer, e que agora nos relatam, como se tivessem acabado de sair de um pesadelo e acordassem para a dura realidade causada pelos seus actos. Esta vingança nunca teve honra, mas, no mundo de Ésquilo, tinha, pelo menos, dignidade.

Uma das opções de Eurípides, particularmente reveladora, é fazer que, na Electra, Orestes nunca regresse à cidade e ao palácio de Argos, executando a vingança nas longínquas montanhas fronteiriças onde, nesta versão, agora vive a sua irmã. Não é possível recuperar o lugar de Agamémnon, e Orestes - que nesta versão já é uma relutante reinvenção de si mesmo - terá de reinventar-se noutro lugar. Mas se, na Electra, o filho de Clitemnestra nunca chega a ver Argos, no Orestes não consegue de lá sair, sujeito a um sofrimento moral e físico que o reduz a um farrapo - em que a presença das Erínias se transforma, acima de tudo, numa luta interior entre o príncipe e a sua consciência - condenado pela voz dúctil de um povo que facilmente se deixa iludir, num julgamento insano pelo modo como desenraíza as premissas do mundo mitológico e as mistura com os preceitos legais da polis, como se as duas realidades 
pudessem coexistir no mesmo plano, sem mutuamente se anularem. Julgar Orestes não o salva, apenas o conduz ao desespero - e por isso o vemos, na companhia de Electra e de Pílades, a optar pelo terrorismo, assaltando o palácio, tentando matar Helena, fazendo Hermíone refém, numa espiral de violência que vai crescendo até se tornar absolutamente insustentável - momento em que Apolo, conspicuamente ausente durante todo o desenvolvimento anterior, intervém para, administrativamente, com a voz poderosa que, ex machina, regula o mundo, colocar ordem em todo aquele caos.

Como se vê por este panorama breve, o caminho da vingança de Orestes, no teatro grego, à medida que se refaz, tende a tornar-se caricatura de si mesmo - e lança, por isso, uma sombra que fica a pairar sobre o próprio Orestes.

A segunda vertente a partir da qual proponho que olhemos Orestes é a da amizade. Quando os Gregos falam de philia, referem-se a uma relação forte, que pode unir partidários da mesma causa, companheiros no campo de batalha ou em outras actividades públicas, bem como membros da mesma família, numa relação, neste caso, solidificada pela partilha de laços de sangue. Falamos, pois, de algo extremamente sólido e firme. Ora, no teatro grego, ganha quase peso proverbial a aliança de philia que une Orestes e Pílades, o príncipe da Fócida que acompanha o filho de Agamémnon no seu percurso de vingança. $\mathrm{O}$ que mais impressiona nesta relação, que apenas conseguimos ver com nitidez no teatro, é a forma como, de tão profunda, parece já prescindir das palavras. Para sermos justos, o silêncio de Pílades pode ser, muitas vezes, justificado pelo facto de a tragédia grega estar limitada a três actores. Mas esta limitação formal, que não deve ser desconsiderada, não explica tudo e, de algum modo, não toma em conta a força que pode ter uma presença silenciosa. Em Ésquilo, em As Coéforas, a presença de Pílades, companhia fiel e longamente muda, já teria sido assimilada como a de um figurante por parte dos espectadores, quando, num momento decisivo em que sobrevem a Orestes um laivo de hesitação, Pílades profere três versos que relembram ao amigo a vontade de Apolo (v. 900-902) e, nessa ocasião, a sua voz tem o ressoar retumbante do inesperado e, ao mesmo tempo, 
ecoa a divindade que, através dela, se faz ouvir. São três versos que quebram a lógica, normalmente presa de alguma rigidez, de distribuição de falas e papéis, ao mesmo tempo que conferem a Pílades uma dimensão tutelar até aí insuspeita - por ser um momento que ninguém certamente anteciparia, vê assim redobrada a sua força emocional. Por isso, é fácil ler a sua presença, aí completa e efectivamente silenciosa, nas duas Electras, a de Sófocles e a de Eurípides, numa dimensão com alguma ressonância provocatória: certamente os espectadores, conhecedores da experiência de Coéforas, acompanhariam ambas as peças à espera do momento em que Pílades proferiria as palavras decisivas, vendo-o, afinal, entrar mudo e sair tão silencioso como entrara. Se já não era possível igualar o efeito da primeira vez, nada como jogar com a expectativa de uma audiência conhecedora e que saberia apreciar a leve provocação.

No entanto, também esta amizade exemplar pode ser questionada. Numa das obras em que prescinde do silêncio, o Orestes, de Eurípides, percebemos que Pílades, o dedicado Pílades, que quer partilhar a sorte do amigo e que se dá a ver como exemplo de philia, foi, afinal, como sublinhou em tempos, muito justamente, Frederico Lourenço (2004), o motor da vingança inicial contra Clitemnestra, tal como é agora o instigador do desvario terrorista no qual Orestes, Electra e ele próprio se envolvem. De silencioso e dedicado cúmplice a sinistro manobrador de um Orestes transformado em marioneta - este novo caminho é bem capaz de subverter uma relação de philia que nos habituámos a considerar como exemplar.

É exactamente a nível do exemplo que se coloca a terceira face de Orestes, para a qual chamo agora a atenção. Orestes pode ser também olhado como modelo, como exemplo a seguir num processo de formação - na Odisseia, ele é apresentado a Telémaco como paradeigma, como aquele que granjeou fama notável (kleos) entre todos os homens, quando matou o assassino de seu pai, o ardiloso Egisto. É mais ou menos com estas palavras que Atena, sob a forma de Mentor, se dirige a Telémaco (cf. I, 298-300). Palavras semelhantes lhe dirige Nestor, em Pilos (cf. III, 196-198), e a mesma ideia volta a ser repetida um pouco adiante (cf. III, 306-308), para que fique bem claro, aos olhos do jovem filho de Ulisses, qual o exemplo que deve seguir. Este exemplo brilha na Odisseia 
porque, como já vimos, à vingança de Orestes é retirada toda a sombra de polémica. Mas, mesmo em Ésquilo, diante de uma escolha terrível, é com absoluta dignidade que Orestes assume o matricídio - e de uma outra maneira, menos linear, o seu comportamento não deixa de ser exemplar. Também neste caso Eurípides nos oferece uma completa reviravolta deste motivo, na Electra, ao colocar Orestes na posição de um Ulisses que regressa para restaurar a ordem na casa da sua família. Mas várias dificuldades se levantam. Por um lado, o jovem príncipe encaixa com visível dificuldade no papel que dele se espera, retarda o reconhecimento, nunca se assume como o vingador em que, quase à força, o querem tornar. Por outro, Electra, a irmã, fantasia o regresso de um Orestes heroico, nitidamente de extracção homérica - e o reconhecimento entre ambos, baseado numa cicatriz, apenas ajuda a simbolizar a desconformidade com o modelo. Como olhar para Orestes, quando é o próprio filho de Agamémnon que se afasta do paradigma que, supostamente, deve representar? Eurípides nunca resolve, propositadamente, este problema e percebemos, por isso, que, no final, a vingança se transforme num crime.

Na peça posterior, Orestes, Eurípides leva as coisas ainda mais longe, quando coloca o jovem príncipe, durante o seu agon com o avô, Tíndaro, a evocar o exemplo de Telémaco, pois o filho de Ulisses, possuidor de uma mãe isenta de mácula, não foi sujeito a sofrimento igual ao seu (cf. v. 588-590). É uma referência breve, mas que não deve ser tomada como inocente ou inócua. ${ }^{1}$ Representa a inversão do paradigma homérico e deve ser lida, simbolicamente, como uma espécie de ponto extremo numa completa revolução no tratamento da figura de Orestes.

Se pensarmos agora, brevemente, no modo com estas três vertentes do desenho de Orestes, ao longo da literatura grega, vão evoluindo, podemos chegar a duas ou três conclusões simples: por um lado, a de que estamos diante de uma personagem complexa, que vive

\footnotetext{
${ }^{1}$ Por isso, não deixa de ser um pouco estranho que passe sem qualquer menção no comentário de Martin West (cf. EURIPIDES; WEST, 1987, p. 222-223). Willink, por seu lado, nota o contraste com a Odisseia, sem daí extrair qualquer conclusão particular (cf. EURIPIDES; WILLINK, 1986, p. 178-179).
} 
acontecimentos terríveis, mas cuja relação com esses acontecimentos, nas várias versões, nunca chega a estabilizar, tornando-a difícil de definir. Podemos dizer, de algum modo, que Orestes vê, ao longo da tradição grega, a construção da sua imagem e a sua destruição. De paradigma e modelo de dignidade rapidamente se volve em retrato distorcido, quase caricatural, de si mesmo. Tudo isto representa, além do mais, uma grande instabilidade, quanto ao olhar que é lançado sobre o filho de Agamémnon. É neste sentido que, quando um autor contemporâneo propõe uma releitura de Orestes e da sua tradição mítica, devemos ter presente que estamos, ele, enquanto autor, nós, enquanto leitores, a mover-nos em território sinuoso e pouco linear. Os três exemplos que brevemente tratarei em seguida ajudarão, certamente, a iluminar o que quero dizer.

Refiro, em primeiro lugar, Um adeus aos deuses, de Ruben A., obra originalmente publicada em 1963 (edição a que não acedi), reeditada em 2010, pela editora Assírio \& Alvim, numa edição preparada por Liberto Cruz, com prefácio de Raul Rosado Fernandes. Trata-se do registo, em forma aproximada à de um diário, de uma viagem à Grécia - mas pode dizer-se que, nestas páginas, não é tanto Ruben A. que viaja pela Grécia, é mais a Grécia que viaja por Ruben A. -; é desse percurso interior, desassombrado, intenso, que sobretudo temos notícia.

Numa obra híbrida, feita de textos de natureza muito diversa, é à sombra do imenso fascínio exercido pelo teatro de Epidauro ${ }^{2}$ que, como um inciso, ancorado no pretexto de uma leitura de Ésquilo feita em voz alta, em pleno teatro, nos aparece um brevíssimo texto dramático, intitulado "O fim de Orestes" (Ruben A. 2010, p. 91-97). É do julgamento de Orestes que se trata, numa espécie de inquietante síntese entre os dois julgamentos que o drama grego nos apresenta, o de Euménides e o de Orestes. O filho de Agamémnon, julgado e absolvido no tribunal de Atenas, salvo pelo voto da deusa, quer regressar a Argos e entregar-se à justiça dos seus concidadãos, uma justiça feita por mortais, e não por divindades. Mas as vozes da multidão condenamno à morte, desconfiadas da protecção divina de que parece gozar - os

\footnotetext{
2 "Epidauro possui o mais belo teatro do mundo e quem puser isto em dúvida é pela única razão de nunca lá ter feito ouvir a sua voz" (RUBEN A., 2010, p. 89).
} 
mortais como ele não suportam que os deuses estejam do seu lado. Numa interessante reviravolta, Orestes vê-se no mesmo desamparo em que o colocou Eurípides, alvo da ira de uma multidão facilmente manobrável, mas desta vez não porque os deuses o tenham abandonado, mas porque permaneceram com ele.

Outra densidade e extensão tem a peça $O$ rancor, de Hélia Correia. Marcada por uma ironia feroz, funciona quase como uma espécie de digest de muita da tradição mítica relacionada com a guerra de Tróia, em particular com a família dos Atridas, aqui apresentada como a mais disfuncional das famílias. ${ }^{3}$ A acção situa-se em Esparta, depois da guerra e do regresso de Tróia, no momento em que Telémaco por lá passa, neste caso a caminho de Delfos, em busca de notícias do pai. Lembramo-nos de imediato do canto IV da Odisseia - e já aí despontava um sinal de subterrânea desarmonia que, apesar do polimento superficial, se inscrevia no modo como Helena e Menelau evocavam Ulisses através de episódios claramente contraditórios entre si (cf. IV, 235-289). Agora, as personagens multiplicam-se - além de Helena e Menelau, também Hermíone e o seu marido Pirro, filho de Aquiles, e ainda Etra, antiga rainha de Atenas, mãe de Teseu, transformada em escrava de Helena como castigo pelo rapto perpetrado por Teseu, mulher que se relaciona com Helena com o arrojo e confiança que decorrem da intimidade normalmente conferida, no teatro grego, às amas. ${ }^{4} \mathrm{O}$ acolhimento a Telémaco cedo deixa estalar a fina camada de verniz com que tentam salvaguardar as aparências e rapidamente se revela um conjunto de figuras que não se suportam mutuamente, que esbracejam, em vão, para manter a harmonia, que jogam aos dados com as tradições do mito, aqui lidas em chave de desconfiança e descrença - a educação de Telémaco, um jovem ingénuo, algo rústico, mas claramente inteligente, vai-se fazendo à custa deste contacto com a podridão, que nenhum enfeite postiço consegue disfarçar durante muito tempo.

\footnotetext{
${ }^{3}$ Para uma análise deste enquadramento mitológico e do modo como é transposto para a presente recriação, veja-se Silva, 2006a.

${ }^{4}$ Esta personagem é desenvolvidamente analisada em Silva $2006 \mathrm{~b}$.
} 
Neste quadro, Orestes chega mais tarde, já a intriga vai bem lançada. Encontramo-lo no seu percurso de purificação após o matricídio, perseguido pelas Erínias, em estado de absoluta desorientação, ele que perdeu os caminhos que o deveriam levar a Delfos e se encaminhou, afinal, na direcção oposta, chegando a Esparta. É um Orestes com aparência de mendigo que encontra, à entrada do palácio de Esparta, uma Helena, irreconhecível, de cabelos rapados, também ela parecendo uma pedinte. O diálogo entre ambos lembra, a espaços, aquele que ocorre entre a rainha de Esparta e Teucro, no início da Helena, de Eurípides. Também aqui Helena é fortemente atacada por alguém que, estando a falar com ela e sobre ela, não a reconhece. Mas mais interessante do que isso é a forma subtil como Hélia Correia vai construindo um subtil laço entre estas duas figuras, um entendimento improvável, que irá, depois, suportar o choque de um reconhecimento tardio, que não deixa de fazer lembrar, pelo tempo que demora, a Electra de Eurípides. Neste processo, extremamente poderoso é o momento em que Orestes, inquieto pelas Erínias, atormentado pela loucura, se acolhe à protecção do regaço de Helena - logo, de todas as pessoas, de Helena - tal como, no Orestes, Eurípides o havia feito acolher-se sob o bem mais provável abrigo constituído por Electra.

Orestes chega, já se disse, sob a aparência de mendigo. A ressonância homérica é evidente e torna-se ainda mais evidente quando vemos este mendigo, que longamente permanece incógnito, a restaurar, de forma inesperada, alguma da ordem daquela casa, encontrando o seu lugar - o lugar possível - naquela família disfuncional. Assim, Orestes mata o improvável pretendente a Hermíone, que assume, neste estranho mundo, a figura do próprio marido da jovem, Pirro, um guerreiro feroz e sem limites, capaz apenas de se alimentar do sangue, do medo, do sofrimento, completamente inadaptado a tempos de paz. Pirro morre às mãos de Orestes e Telémaco, numa aliança onde, de acordo com o paralelo feito, brilham ainda as reminiscências homéricas.

Quando tudo se recompõe, Hélia Correia faz a intriga voltar ao princípio - e nisso a identifica com a sina das narrativas gregas, sempre a voltarem ao início, sempre sucessivamente retomadas - e, nesse 
momento, é já Orestes quem ocupa o lugar de Pirro, junto de Hermíone. As Erínias, dulcificadas, apaziguadas, são agora escravas de Helena. Compostos os enfeites, retocados os sorrisos, acolhem de novo o filho de Ulisses, agora forçosamente já menos inocente. E talvez seja essa a noção fundamental, quando somos colocados diante de recriações, como esta, de um conjunto de mitos da antiguidade: a inocência, o encanto inocente com que se sorviam estas histórias, não é possível nos dias de hoje. Em rigor, também já não o era no tempo de Eurípides.

Uma última referência, mais breve, à peça $O$ irmão, de David Mourão-Ferreira, também já lida, em devido tempo, de forma atenta e aguda, por Maria Fernanda Brasete (1997). Esta obra de Mourão-Ferreira foi publicada pela primeira vez em 1963, representada em 1970, pelo Teatro do Salitre, republicada em 1996 (cf. BRASETE, 1997, p. 45).

Com acção localizada num meio burguês do início da segunda metade do século XX, no tempo simbólico de uma noite de Natal, a peça mostra-nos uma mulher, Bárbara, que espera um irmão que ninguém parece conhecer ou saber sequer se existe. A intriga, que se desenvolve por duas vezes, em sucessão, seguindo percursos paralelos - mais uma vez, como se fosse uma absoluta necessidade, este recurso, tão próximo da antiguidade, a enredos que insistentemente se renovam -, nunca nos deixa saber se aquele irmão existe mesmo ou se é apenas uma vontade muito funda, ou eventualmente uma manipulação, desta particular Electra. O ruído da porta que se abre, que encerra a acção de cada acto, sem que nunca saibamos quem chega, deixa-nos propositadamente sem suficiente resposta.

Fica aqui desenhada, nesta experiência dramática, uma outra linha de leitura particularmente importante quando pensamos no mito do filho de Agamémnon: o Orestes que não está, o Orestes que ainda não chegou. Orestes é também esse vazio que, durante anos, se faz esperar, existe apenas sob a forma de um nome, de uma ansiedade, de uma incerteza. O Orestes que existe na espera é uma tela em branco, que a angústia dos que esperam desenha de acordo com as suas cores. Pode ser a serpente que aterroriza o sono ou o guerreiro que acalenta os sonhos de vingança. Resta sempre saber se Orestes está à altura da espera. 
No mundo dos Gregos, ainda que se faça esperar, Orestes acaba por chegar, mesmo quando o faz de forma improvável. "Talvez ele venha", diz um relutante Orestes, falando de si mesmo, em diálogo com uma impaciente Electra, em Eurípides. "Mas, tu és mesmo ele?", pergunta a mesma Electra, depois do reconhecimento, quando a sorte lhe põe diante dos olhos aquele inusitado Orestes. ${ }^{5}$ Nos dias de hoje, não é improvável que Orestes seja apenas uma sombra, um desejo - afinal, e de acordo com tempos tão vazios, uma ausência.

Recuemos agora um pouco, até às três vertentes sob as quais, neste breve trabalho, foi enquadrada a figura de Orestes: vingança, amizade, educação. O percurso de cada uma delas, ao longo da literatura grega, foi no sentido de uma progressiva degradação, como se fosse impossível a Orestes - e à sua história - manterem, à sombra de progressivas recriações, a sua feição modelar e paradigmática. Quando passamos para as recriações contemporâneas, notamos que duas dessas vertentes (a amizade, a educação) perdem força, de modo tal que não se dá por elas. Sobra a vingança, de todas a mais forte, a mais definidora. Mas também aqui o papel de Orestes se dilui, a vingança passa apenas a expiação e constante sofrimento, não há no seu acto qualquer lampejo de grandeza. Ou então, e essa é a forma extrema de diluir Orestes, ele transforma-se apenas numa sombra, uma ausência que alimenta um fogo dificilmente capaz de arder sem ela.

Multiplicar Orestes parece tirar-lhe nitidez. O retrato, como já vimos, esbate-se, os contornos parecem desafiar a acuidade da nossa visão. Mas quando o reencontramos, às vezes só uma pequena marca, outras vezes mais legível, mais intenso, há uma luz que, continuamente alimentada, nunca deixa de brilhar.

\section{Referências}

BRASETE, M. F. Sobrevivência e renovação da tragédia em $O$ irmão de David Mourão Ferreira. In: TORRÃO, J. M. (Org.). COLÓQUIO

\footnotetext{
${ }^{5}$ As duas breves citações encontram-se, respectivamente, nos versos 399 e 581 da Electra, de Eurípides.
} 
CLÁSSICO, 2., 1997, Aveiro. Actas... Aveiro: Universidade de Aveiro, 1997. p. 45-64.

CORREIA, H. O rancor. Lisboa: Relógio D’Água, 2000.

EURIPIDES; WEST, M. L. (Ed.). Euripides: Orestes. Warminster: Aris \& Phillips, 1987.

EURIPIDES; WILLINK, C. W. (Ed.). Euripides: Orestes. Oxford:Clarendon Press, 1986. DOI: https://doi.org/10.1093/actrade/9780198143963.book.1

LOURENÇO, F. Bons e maus amigos no Orestes de Eurípides. In:

Grécia revisitada. Lisboa: Cotovia, 2004. p. 146-152.

MOURÃO-FERREIRA, D. O irmão. Lisboa: D. Quixote, 1996.

RUBEN A. Um adeus aos deuses. Lisboa: Assírio \& Alvim, 2010.

SILVA, M. de F. A ama - um motivo clássico no Rancor de Hélia Correia. In: . (Coord.). Furor: ensaios sobre a obra dramática de Hélia Correia. Coimbra: Imprensa da Universidade de Coimbra, 2006b. p. 115128. DOI: https://doi.org/10.14195/978-989-26-0391-9_8

SILVA, M. de F. Mitos em crise. Hélia Correia, O Rancor. In:

(Coord.). Furor: ensaios sobre a obra dramática de Hélia Correia. Coimbra: Imprensa da Universidade de Coimbra, 2006a. p. 93-113. DOI: https://doi.org/10.14195/978-989-26-0391-9_7 